\title{
Numerical and Experimental Studies of High Strain Rate Mechanical Behavior of E-Glass/Polyester Composite Laminates
}

\author{
Gozde TUNUSOGLU \\ Dynamic Test and Modeling Laboratory \\ Department of Mechanical Engineering \\ Izmir Institute of Technology \\ Izmir, Turkey
}

\author{
Mustafa GUDEN \\ Dynamic Test and Modeling Laboratory \\ Department of Mechanical Engineering \\ Izmir Institute of Technology \\ Izmir, Turkey
}

\author{
Alper TASDEMIRCI \\ Dynamic Test and Modeling Laboratory \\ Department of Mechanical Engineering \\ Izmir Institute of Technology \\ Izmir, Turkey
}

I. W. HALL

Department of Mechanical Engineering

University of Delaware

Newark, DE, USA

\section{ABSTRACT}

Quasi-static $\left(\sim 10^{-3} \mathrm{~s}^{-1}\right)$ and high strain rate $\left(\sim 850 \mathrm{~s}^{-1}\right)$ compression behavior of an E-glass/polyester composite was determined in the through-thickness and in-plane directions. In both directions, modulus and failure strength increased with increasing strain rate. Higher strain rate sensitivity for both elastic modulus and failure strength was observed in the inplane direction. A numerical model was developed to investigate the compressive deformation and fracture of an Eglass/polyester composite. Excellent agreement was demonstrated for the case of high strain rate loading. Also, the fracture geometries were successfully predicted with the numerical model.

\section{INTRODUCTION}

A variety of studies addressed composite failure modeling under dynamic loading, e.g., [1-7]. Some of these used the Split Hopkinson Pressure Bar (SHPB) to investigate the high strain rate mechanical properties of composites under compressive, tensile and shear loading, while others used other techniques such as drop-weight testing. Studies utilizing various versions of the SHPB to characterize dynamic mechanical properties of composites at high strain rates have mainly been concentrated on specimen geometry, through thickness stitching, fiber orientation, and strain rate effects.

In this study, quasi-static $\left(\sim 10^{-3} \mathrm{~s}^{-1}\right)$ and high strain rate $\left(\sim 850 \mathrm{~s}^{-1}\right)$ compression behavior of an E-glass/polyester composite were determined. The compression, tension and shear behavior of similar composite different in fiber architecture and/or fiber volume fraction were previously studied at quasi-static and high-strain rates [8-13].

The present study focused on the use of SHPB as a means of validating the material model as well as generating reliable mechanical property data and investigating damage initiation and progression.

\section{EXPERIMENTS AND MODELING}

E-glass fiber woven fabric $\left(0.6 \mathrm{~kg} / \mathrm{m}^{2}\right)$-Crystic $702 \mathrm{PAX}$ polyester composite plates, $12 \mathrm{~mm}$ in thickness, were prepared using the vacuum assisted resin transfer molding process at the Dynamic Testing and Modeling Laboratory, Izmir Institute of Technology. Cylindrical composite samples, $9.5 \mathrm{~mm}$ in diameter, were core-drilled from the composite plates throughthickness (normal to the fiber plane) and in-plane directions as shown in Figs. 1(a) and (b). 


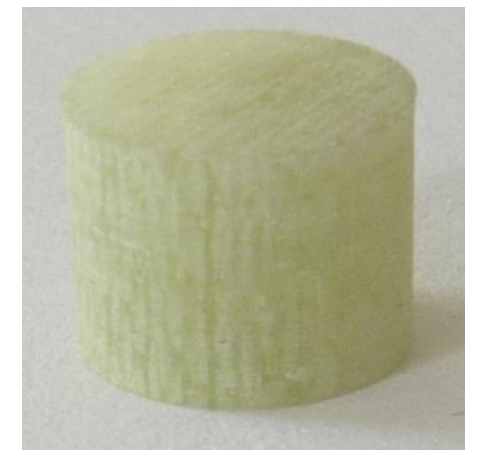

(a)

(b)

Figure. 1. CYLINDIRICAL COMPOSITE SAMPLES: (a) IN-PLANE and (b) THROUGH THICKNESS DIRECTIONS.

Samples were compression tested quasi-statically at a strain rate of $10^{-3} \mathrm{~s}^{-1}$ using a Shimadzu AG-I testing machine and dynamically at an average strain rate of $850 \mathrm{~s}^{-1}$ using a compression SHPB apparatus. The particular SHPB apparatus used consists of CPM Rex $76^{\mathrm{TM}}$ bars, a $350 \mathrm{~mm}$ long striker bar, a $3600 \mathrm{~mm}$ incident bar and a $1800 \mathrm{~mm}$ transmitter bar, all with a diameter of $20.35 \mathrm{~mm}$. The multiple reloading of the samples in SHPB was avoided by using a transmitter bar shorter than the incident bar. The strain rate $(\dot{\varepsilon})$, the strain $(\varepsilon)$ and the stress of the tested samples were calculated using the following equations:

$$
\begin{aligned}
& \dot{\varepsilon}(t)=-\frac{2 C_{b}}{L_{s}} \varepsilon_{r}(t) \\
& \varepsilon(t)=-\frac{2 C_{b}}{L_{s}} \int_{0}^{t} \varepsilon_{r}(t) d t \\
& \sigma(t)=\frac{E_{b} A_{b}}{A_{s}} \varepsilon_{t}(t)
\end{aligned}
$$

where, $C_{b}$ is the elastic wave velocity of the bar, $L_{s}$ is the sample length and $A_{s}$ and $A_{b}$ are the sample and bar crosssectional area, respectively. $\varepsilon_{\mathrm{i}}, \varepsilon_{\mathrm{r}}$ and $\varepsilon_{\mathrm{t}}$ are incident, reflected and transmitted strains measured from strain gages on the bar, respectively. The above equations are based on the assumption that the forces at sample-bar interfaces are equal. The force equilibrium for the same incident and transmitter bar diameter is expressed as

$$
\sigma_{t}(t)=\sigma_{i}(t)+\sigma_{r}(t)
$$

where, $\sigma_{\mathrm{t}}, \sigma_{\mathrm{i}}$ and $\sigma_{\mathrm{r}}$ are the transmitted, incident and reflected stresses, respectively. The left and right side of this equality are used in the so-called "one-wave" and "two-wave" analysis, respectively.

The commercial explicit finite element code LS-DYNA 971 was used for three-dimensional SHPB finite element modeling. MAT162 was assigned to model the composite specimen. This material model is based on the principle of progressive failure of Hashin [14] and damage mechanics of Matzenmiller et al. [15] that incorporates features for controlling strain softening after failure. MAT162 needs nine elastic constants $\left(E_{A}, E_{B}, E_{C}, \vartheta_{B A}, \vartheta_{C A}, \vartheta_{C B}, G_{A B}, G_{B C}, G_{C A}\right)$ and also needs ten strength-related parameters $\left(S_{A T}, S_{A C}\right.$, $\mathrm{S}_{\mathrm{BT}}, \mathrm{S}_{\mathrm{BC}}, \mathrm{S}_{\mathrm{CT}}, \mathrm{S}_{\mathrm{FS}}, \mathrm{S}_{\mathrm{FC}}, \mathrm{S}_{\mathrm{AB}}, \mathrm{S}_{\mathrm{BC}}, \mathrm{S}_{\mathrm{CA}}$ ) to define the yield after elastic deformation, two material parameters (SFFC, PHIC) to define residual strength after compression and Mohr-Coulomb type friction angle, two model-dependent variables (S_DELM, OMGMX) to define stress concentration at the delamination front and maximum admissible modulus reduction, and three erosion parameters (E_LIMT,E_CRSH, EEXPN) for eroding elements to allow penetration or to create new surfaces. There are several failure criteria to define different damage modes, e.g., tensile and compressive fiber failure, fiber crushing, through thickness matrix failure and delamination. MAT162 has the capability of modeling post-damage softening behavior of composites using continuum damage mechanics principles while degrading the material properties. This method of progressive damage is attained using an exponential damage function with the softening parameter "AM" for four different damage modes, e.g., AM1 for fiber damage in the material direction A, AM2 for fiber damage in material direction $\mathrm{B}, \mathrm{AM} 3$ for fiber crushing, and AM4 for matrix crack and delamination. Mat162 also accounts for the strain rate effects (CERATE's) in tension, compression and shear which can be used for simulation in high strain rate deformation events.

The numerical methodology followed in this paper consists of two phases: a) a series of single element simulations under uniaxial stress condition and b) SHPB test numerical simulations. There is no clearly defined procedure for calibrating damage growth and post-failure softening. Thus, parametric simulations were conducted for different loading and boundary conditions, e.g., in-plane compression and transverse compression. As a first step, a single-element model loaded in compression in the in-plane direction was used to observe the effect of different values of AM1 and AM2, a value of 2 for both giving the best representation of the post-failure behavior. From the through-thickness compression model, damage parameter, AM3, was set to 0.5 to represent the abrupt fiber failure observed in the experiments. However, selection of the value for the shear damage parameter is not as straightforward. A 0.35 value of AM4 reported in [16] was used 
in the present study. There are some other properties that have to be fine tuned by comparing simulations with SHPB experiments presented in this paper while keeping the known properties constant throughout the calibration. The parameters that need to be calibrated are out-of-plane fiber and matrix shear strengths and the delamination constant. In a recent experimental work conducted on plain-weave E-glass/epoxy composite [11], interlaminar shear strength was measured to be $29.4 \mathrm{MPa}$ at an average strain rate of $1000 \mathrm{~s}^{-1}$. In the same study, strain-rate sensitivity of interlaminar shear strength was also discussed. In this research, $30 \mathrm{MPa}$ was used as the baseline value of interlaminar shear strength. The throughthickness tensile strength of the composite was estimated to be $50 \mathrm{MPa}$. Experimental results revealed that the throughthickness tensile strength of the composite is usually lower than the tensile strength of the polyester matrix material. The interlaminar shear stress concentration was studied by Pahr et al. [17] and the stress concentration was reported to be 1.21. In this study, a value of 1.2 was used for the delamination constant.

The effect of strain rate on the ply strength is modeled by strain rate dependent functions expressed as [18]:

$$
\left\{\mathrm{S}_{\mathrm{rt}}\right\}=\left\{\mathrm{S}_{0}\right\}\left(1+\mathrm{C}_{1} \ln \frac{\dot{\bar{\varepsilon}}}{\dot{\varepsilon}_{0}}\right)
$$

where $C_{1}$, is the strain rate constant for strength properties, $\left\{\mathrm{S}_{\mathrm{rt}}\right\}$ are the rate dependent strength values, $\left\{\mathrm{S}_{0}\right\}$ are the quasistatic reference strength values, $\dot{\varepsilon}_{0}$ is the quasi-static reference strain rate, and $\dot{\bar{\varepsilon}}$ are the associated strain rates.

For the rate dependent stiffness properties:

$$
\left\{\mathrm{E}_{\mathrm{rt}}\right\}=\left\{\mathrm{E}_{0}\right\}\left(1+\mathrm{C}_{\mathrm{i}} \ln \frac{\dot{\bar{\varepsilon}}}{\dot{\varepsilon}_{0}}\right) \quad \mathrm{i}=2, \ldots, 4
$$

where $\left\{\mathrm{E}_{\mathrm{rt}}\right\}$, are the rate dependent stiffness values, $\left\{\mathrm{E}_{0}\right\}$ are the quasi-static stiffness values, $\mathrm{C}_{2} \mathrm{C}_{3}$ and $\mathrm{C}_{4}$ are the strain rate constants for the longitudinal, shear and transverse modules, $\dot{\varepsilon_{0}}$ is the reference strain rate, and $\dot{\bar{\varepsilon}}$ are the associated strain rates. Based on the experimental data given in the present study, values of $\mathrm{C}_{1}=0.014, \mathrm{C}_{2}=0.040$ and $\mathrm{C}_{4}=0.0284$ for $\mathrm{E}$ glass/polyester composite were calculated and used in the present paper as baseline strain rate sensitivity constants. A 0.030 value of $\mathrm{C}_{3}$ was calculated from the experimental data given in [11]. Beside the above mentioned material properties and parameters, three eroding parameters need to be determined. The three eroding parameters, E_LIMIT, E_CRSH, and EEXPN, were obtained from fine tuning them to match up the bar responses and final deformed shapes of the specimens for both in-plane and through-thickness tests. The material properties used in the simulation for the composite specimen are shown in Table 1 and the bars in Table 2.
Table 1

Material properties of E-glass/polyester composite

\begin{tabular}{|l|l|}
\hline Density, $\rho,\left(\mathrm{kg} \mathrm{m}^{-3}\right)$ & 1850 \\
\hline Tensile modulus, $\mathrm{E}_{\mathrm{A}}, \mathrm{E}_{\mathrm{B}}, \mathrm{E}_{\mathrm{C}},(\mathrm{GPa})$ & $18.2,18.2,6.2$ \\
\hline Poisson's ratio, $\vartheta_{\mathrm{BA}}, \vartheta_{\mathrm{CA}}, \vartheta_{\mathrm{CB}}$ & $0.08,0.14,0.15$ \\
\hline Shear modulus, $\mathrm{G}_{\mathrm{AB}}, \mathrm{G}_{\mathrm{BC}}, \mathrm{G}_{\mathrm{CA}},(\mathrm{GPa})$ & $1.79,1.52,1.52$ \\
\hline In-plane tensile strength, $\mathrm{S}_{\mathrm{AT}}, \mathrm{S}_{\mathrm{BT}},(\mathrm{GPa})$ & 0.4 \\
\hline Out of plane tensile strength, $\mathrm{S}_{\mathrm{CT}},(\mathrm{GPa})$ & 0.05 \\
\hline Compressive strength, $\mathrm{S}_{\mathrm{AC}}, \mathrm{S}_{\mathrm{BC}},(\mathrm{GPa})$ & 0.33 \\
\hline Fiber crush, $\mathrm{S}_{\mathrm{FC}},(\mathrm{GPa})$ & 0.5 \\
\hline Fiber shear, $\mathrm{S}_{\mathrm{FS}},(\mathrm{GPa})$ & 0.2 \\
\hline $\begin{array}{l}\text { Matrix mode shear strength, } \mathrm{S}_{\mathrm{AB}}, \mathrm{S}_{\mathrm{BC}}, \mathrm{S}_{\mathrm{CA}}, \\
(\mathrm{GPa})\end{array}$ & 0.03 \\
\hline $\begin{array}{l}\text { Residual compressive scale factor, SFFC, } \\
(\mathrm{GPa})\end{array}$ & 0.3 \\
\hline Friction angle, PHIC, $(\mathrm{GPa})$ & 10 \\
\hline Damage parameter, AM1, AM2, AM3, AM4 & $2.0,2.0,0.5,0.35$ \\
\hline Strain rate parameter, $\mathrm{C}_{1}, \mathrm{C}_{2}, \mathrm{C}_{3}, \mathrm{C}_{4}$ & 0.014, \\
\hline Delamination, S_DELM & $0.040,0.03$, \\
\hline Eroding strain, E_LIMIT & 0.2 \\
\hline
\end{tabular}

Table 2

Material properties for the incident and transmitter bars

\begin{tabular}{|l|l|}
\hline Density, $\rho,\left(\mathrm{kg} \mathrm{m}^{-3}\right)$ & 8255 \\
\hline Young's modulus, E, $(\mathrm{GPa})$ & 214 \\
\hline Poisson's ratio, $\theta$ & 0.3 \\
\hline
\end{tabular}

In the damage analysis of a composite specimen, a full (no symmetry definitions) numerical model was used with appropriate boundary conditions. The model has three components in contact: the incident and transmitter bars each $1524 \mathrm{~mm}$ in length, and the specimen. Experimentally measured stress pulse is used as an input to the impact face of the incident bar and all other boundaries are traction-free. The finite element mesh of SHPB model is shown in Fig. 2. In order to reduce computation time, the simulation uses $1524 \mathrm{~mm}$ length of the bars instead of full length. Although this decreases the transit time between successive waves and shortens the wave duration slightly, it does not affect the basic wave shapes or amplitudes. Trial computations were carried out using fulllength bars but, apart from the slightly smaller time window, no significant differences were found and the shorter bars were used in all calculations henceforth. Incident and transmitter bars models are composed of 60000 elements. Through-thickness and in-plane composite specimens were modeled with 83520 and 72000 elements, respectively. Eroding single surface contact was defined between the bar ends and the specimen. 


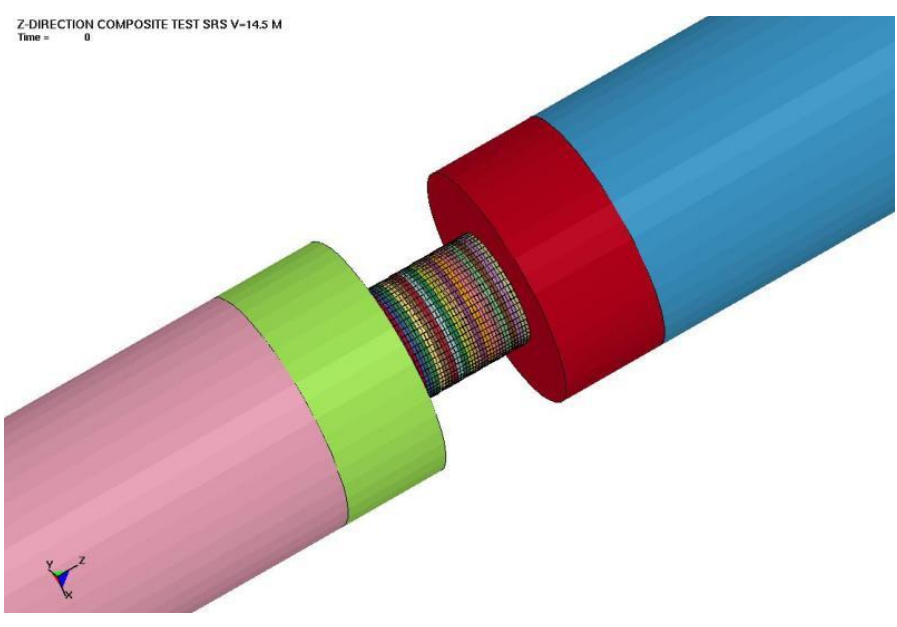

Figure. 2. FEM of SHPB MODEL.

Early development and validation of the model have been previously reported for the numerical and experimental damage analysis of S2-glass/SC-15 composite material using MAT162. The present report focuses on the damage and fracture in Eglass/polyester composite material. The material model capability is verified by comparing experimental SHPB testing and simulation. The verification is based on the details of wave propagation and damage generation inside the composite samples. The model can also be used to determine local deformation at any point within the sample. This information may also be used to investigate the locations of the delaminations and fracture initiation and the local stress and strain gradients and stress discontinuities. Since, the fracture of composites is highly statistical in nature and depends on the local population of the defects; the developed models cannot exactly reproduce the actual fracture behavior. However, the numerical model accurately reproduces the general appearance of fracture path as observed by post mortem fractographic analyses: it thus achieves the main thrust of the present simulations which is to understand when and where damage starts and to see how it propagates. Scanning electron and optical microscopy techniques were further performed on the tested and failed samples to determine operative failure modes and results were compared with those of numerical simulations.

\section{RESULTS AND DISCUSSION}

Typical stress-strain curves of the composite at quasi-static and high strain rates are shown in Figs. 3 and 4 for in-plane and through-thickness directions, respectively.

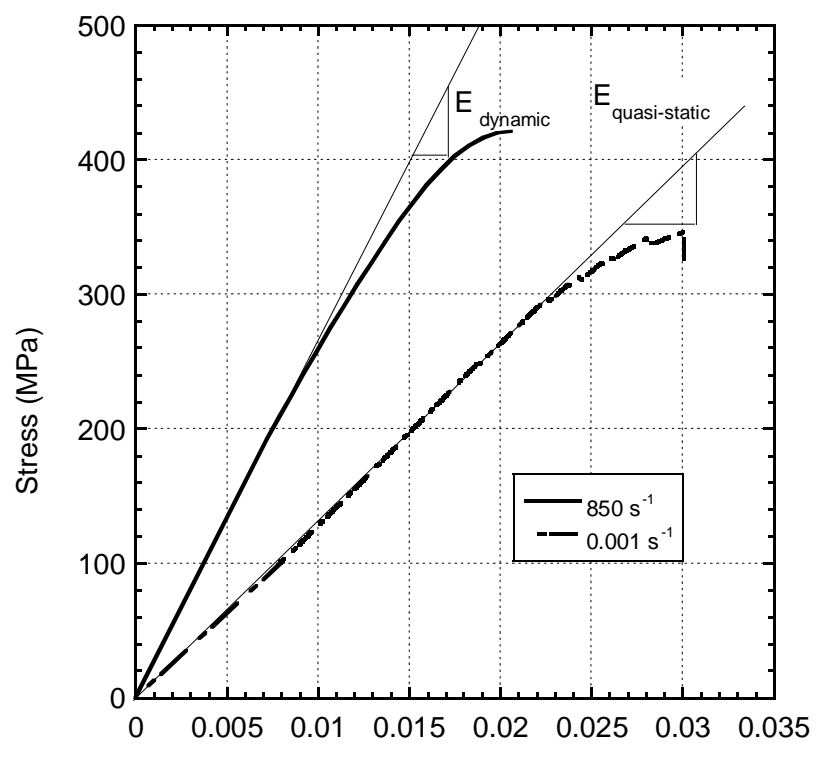

$\begin{array}{lrrrr}\text { Figure. 3. } & \text { STRESS-STRAIN } & \text { CURVES of } & \text { THE } \\ \text { COMPOSITE IN IN-PLANE } & \text { DIRECTION } & \text { AT } \\ \text { DIFFERENT STRAIN RATES. } & & & \end{array}$

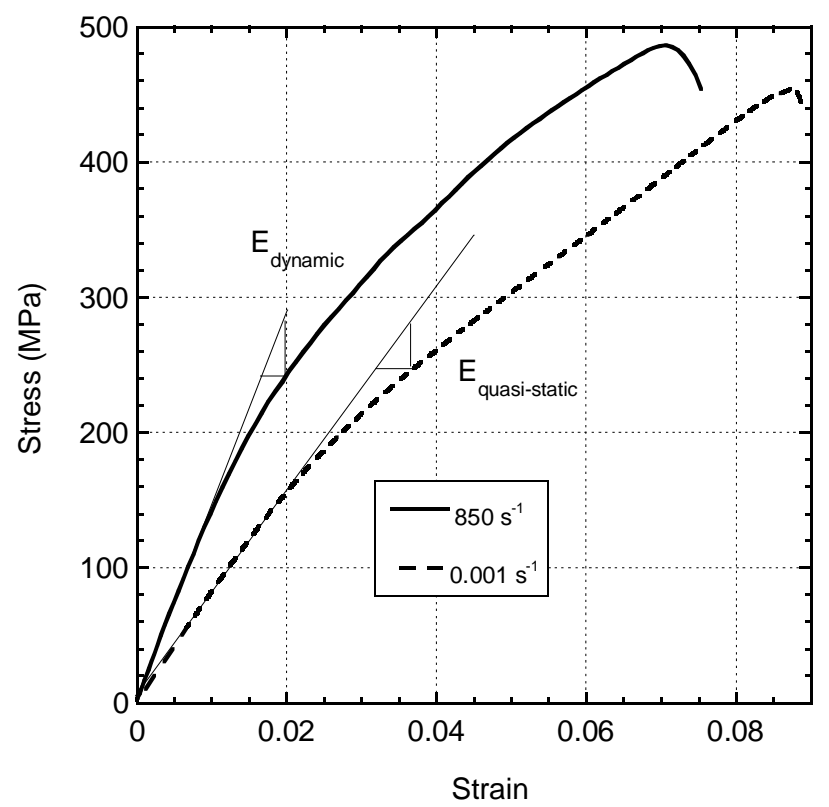

Figure.4.STRESS-STRAIN CURVES of THE COMPOSITE IN THE THROUGH-THICKNESS DIRECTION. 
The curves are almost linear at the beginning of the deformation then become non-linear as the strain increases. The modulus of the composite specimens was calculated in the linear region of the curves, as depicted in Figs. 3 and 4, and used to determine the strain rate sensitivity of the modulus of composite for in-plane and through-thickness directions. The peak points on these figures are considered as the failure stresses and the corresponding strains as the failure strains.

The variation of the modulus of the composite with strain rate is shown in Fig. 5. The modulus is seen in the same figure and exhibits strain rate sensitivity in both directions within the studied strain rate regime.

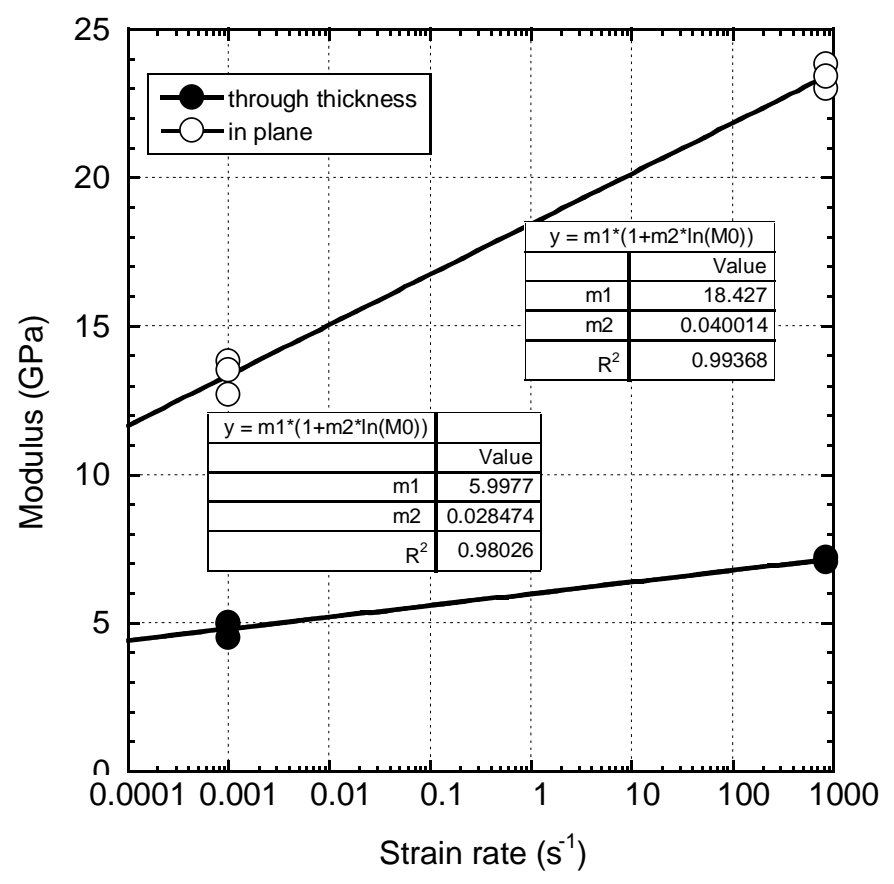

Figure. 5. MODULUS vs STRAIN RATE IN IN-PLANE and THROUGH-THICKNESS DIRECTIONS.

The average modulus of the composite increases from 13.0 to $22.0 \mathrm{GPa}$ in the in-plane direction and from 4.8 to $7.1 \mathrm{GPa}$ in the through thickness direction as the strain rate increases from quasi-static $\left(1.0 \times 10-3 \mathrm{~s}^{-1}\right)$ to high strain rates $\left(>800 \mathrm{~s}^{-1}\right)$. As can be seen from the figure, there is a higher strain rate sensitivity of the elastic modulus in the in-plane direction. The compressive failure stress of the composite also showed strain rate sensitivity in the strain rate range investigated (Figs. 6(a)\&(b)), 330-420 MPa in the in-plane direction and 430-490 $\mathrm{MPa}$ in the through thickness direction, showing a higher strain rate sensitivity of the failure stress in the in-plane direction.

The average failure strains show strain rate dependence as well: in the in-plane direction, the failure strain decreases as the strain rate increases from 0.025 at $1.0 \times 10-3 \mathrm{~s}^{-1}$ to 0.020 at 850 $\mathrm{s}^{-1}$. In addition, the average failure strain in the through- thickness direction decreases slightly with strain rate from quasi-static to high strain rates: 0.085 at $1.0 \times 10-3 \mathrm{~s}^{-1}$ to 0.073 at $850 \mathrm{~s}^{-1}$. Figs. 7 and 8 show typical photographs of the failed samples tested at quasi-static and high strain rates in the inplane and through-thickness directions.

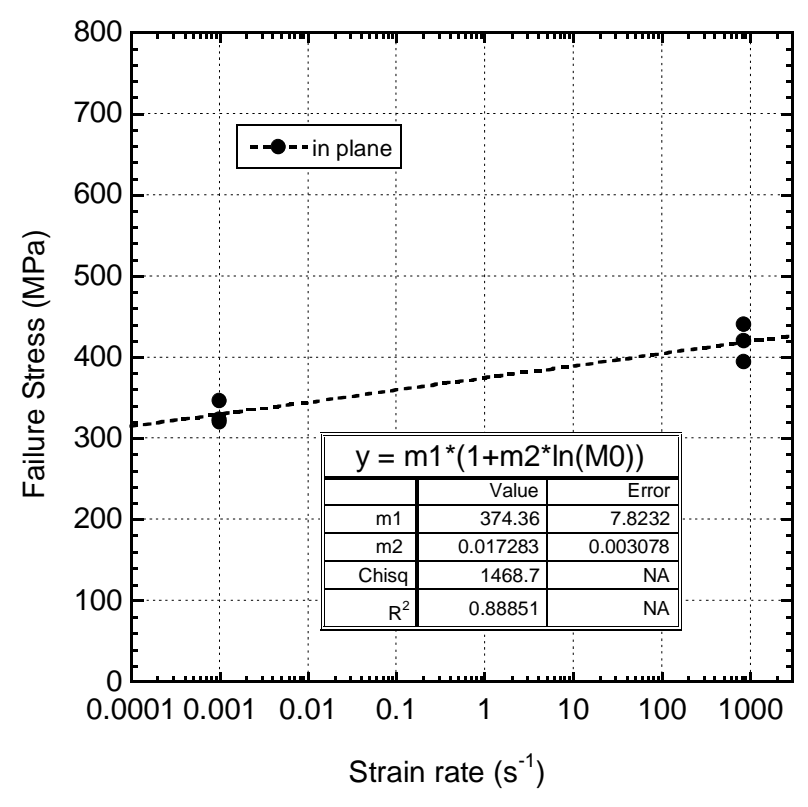

(a)

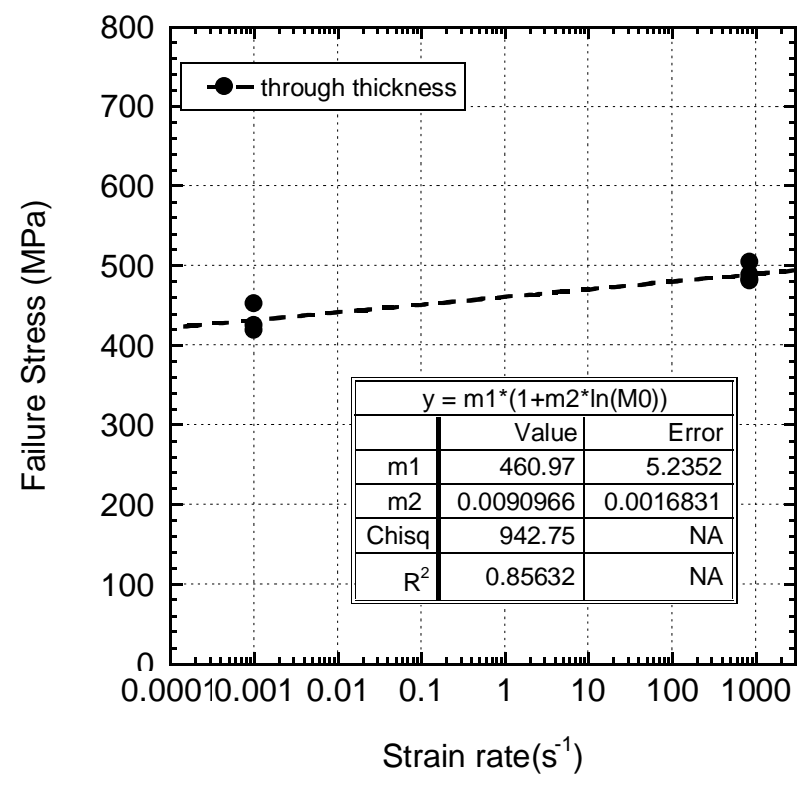

(b)

Figure. 6. STRESS vs STRAIN RATE IN: (a) IN-PLANE and (b) THROUGH-THICKNESS DIRECTIONS. 


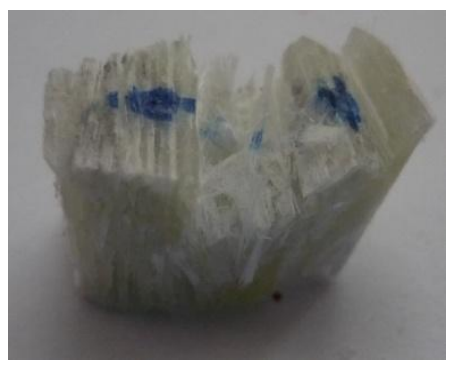

(a)

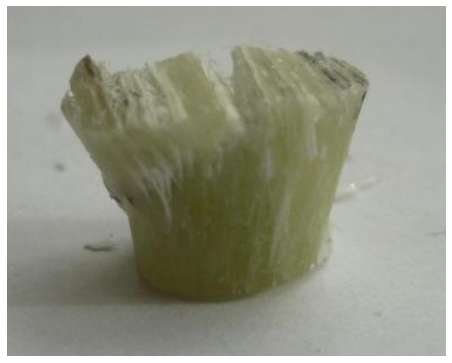

(b)
Figure. 7. PHOTOGRAPHS of SAMPLES TESTED IN THE IN-PLANE DIRECTION: (a) QUASI-STATIC and (b) HIGH STRAIN RATE.

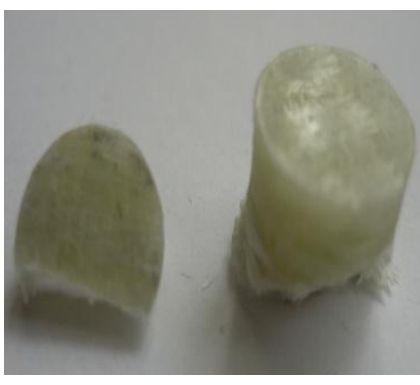

(a)

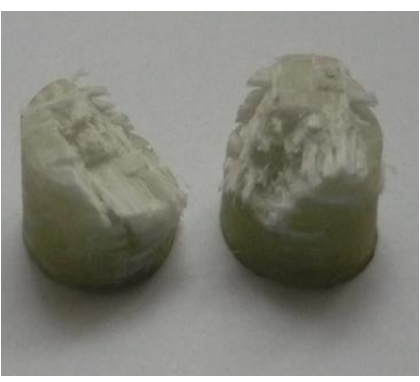

(b)
Figure. 8. PHOTOGRAPHS of SAMPLES TESTED IN THE THROUGH-THICKNESS DIRECTION: (a) QUASI-STATIC and (b) HIGH STRAIN RATE.

Both the maximum strain and maximum stress for the specimen along in-plane direction are less than those along the through-thickness direction due to operation of the different failure modes. For the specimen along the in-plane direction, under both quasi-static and high strain rate loading, the specimen failure is predominantly by delamination between the fibers and resin, indicating low interfacial strength between the fiber and the resin. At high strain rate, in particular, the specimens split along the loading direction, which is aligned with the direction of the fibers. In the through-thickness direction, at high strain rates, extensive cracking occurs at interlaminar boundaries, resulting in adjoining layers being displaced and extruded in different directions and giving rise to two major fragments and several smaller ones. Cracks are initiated between the fiber layers (Fig. 9) and also progressive shear cracks are observed in the matrix.

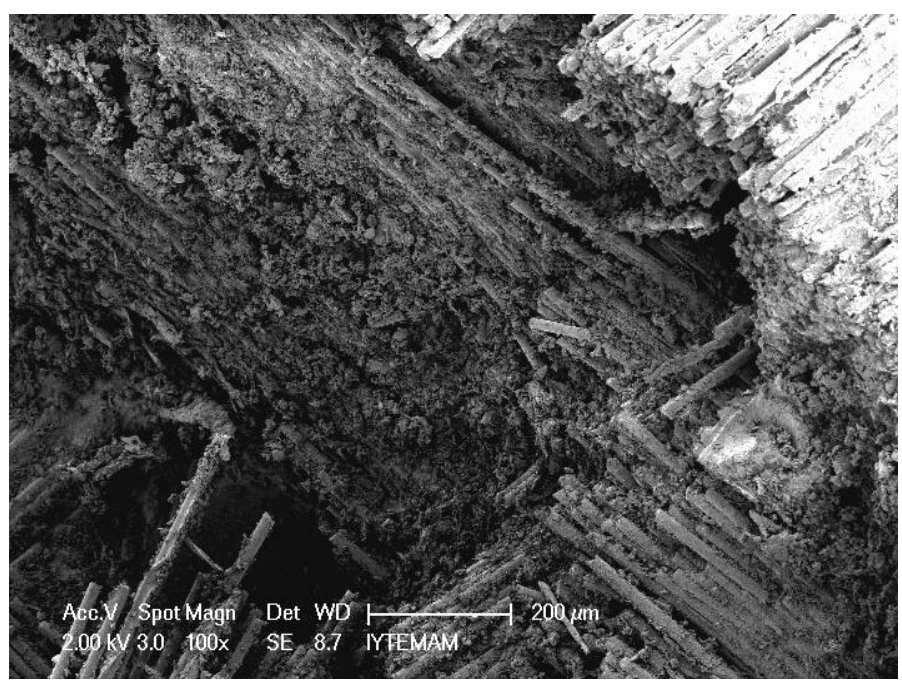

Figure. 9. SEM IMAGE of FAILED SPECIMEN TESTED IN THE THROUGH-THICKNESS DIRECTION.

Figs. 10(a) and (b) show experimental and numerical results, respectively for an SHPB experiment conducted with a striker bar velocity of $14.5 \mathrm{~m} / \mathrm{s}$, corresponding to an average strain rate of $850 \mathrm{~s}^{-1}$ for the through-thickness direction.

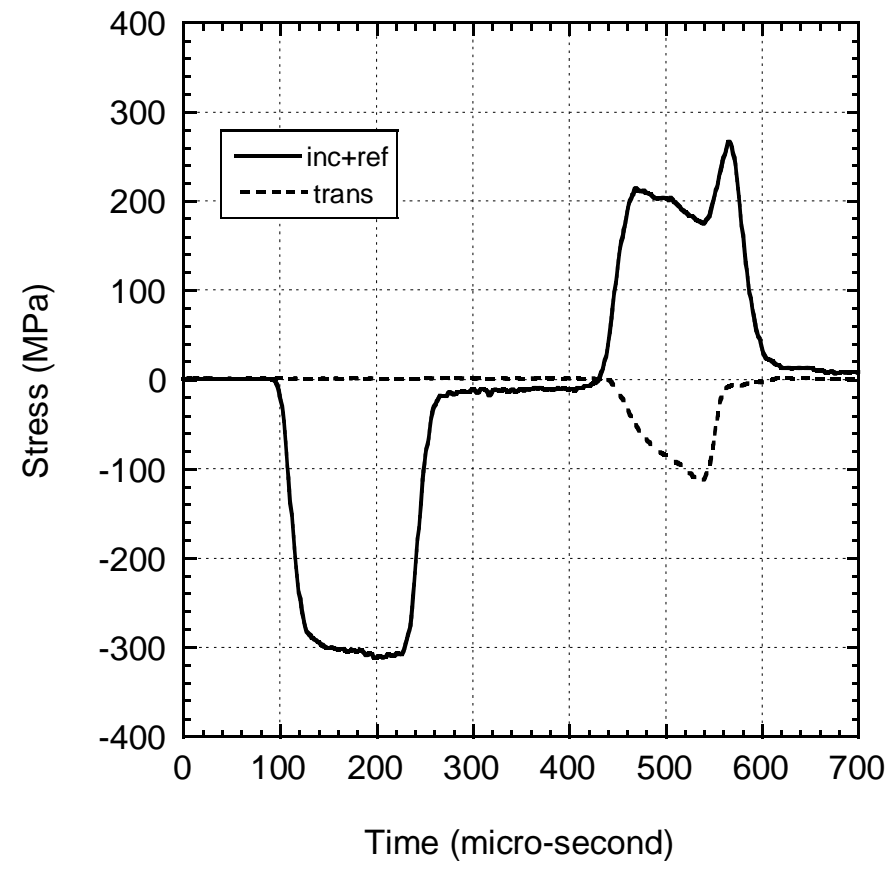

(a) 


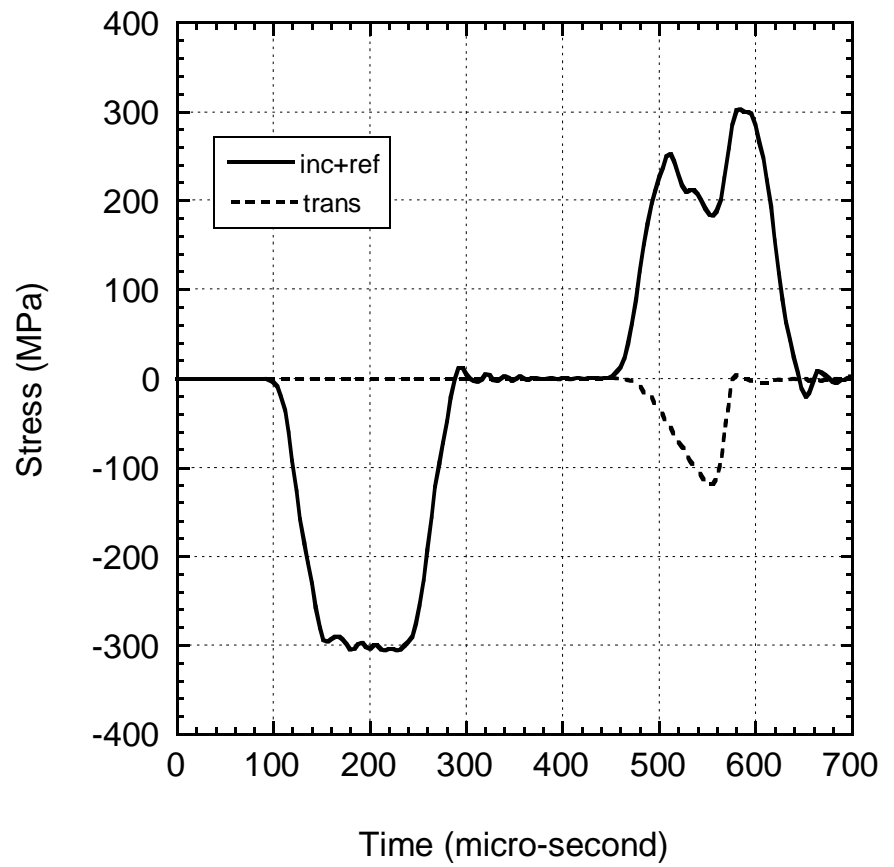

(b)

Figures. 10. SHPB RESULTS IN THE THROUGH THICKNESS DIRECTION: (a) EXPERIMENTAL and (b) NUMERICAL.

The amplitude of the reflected wave is seen to increase as a function of time from zero to a local maximum before decreasing gradually: this is followed by a sharp rise indicating that the specimen has been extensively damaged or has failed. The numerical data of Fig. 10(b) are very similar to those of experimental data and, hence, confirm the validity of the model.

Figs. 11(a) and (b) show experimental and numerical SHPB waves of the in-plane specimen. The reflected wave increases from zero to a local maximum then decreases slightly, indicating the specimen failure during the test. Figs. 12(a) and (b) show numerically deformed specimens in the through thickness and in-plane directions, respectively. For the specimen deformed in the through-thickness direction, simulation shows the form of severe delamination, matching excellently with the actually observed damage modes (Fig. 8(b)). The longitudinal compressive strain generated lateral strains which promoted the development of interlaminar matrix cracks. Fiber bundles flowed outward from the specimen and eventually the specimen disintegrated catastrophically. The inplane specimen failed by axial splitting in two or more pieces along the loading direction. The numerical model accurately reproduced, therefore, the final appearance of fractured sample.

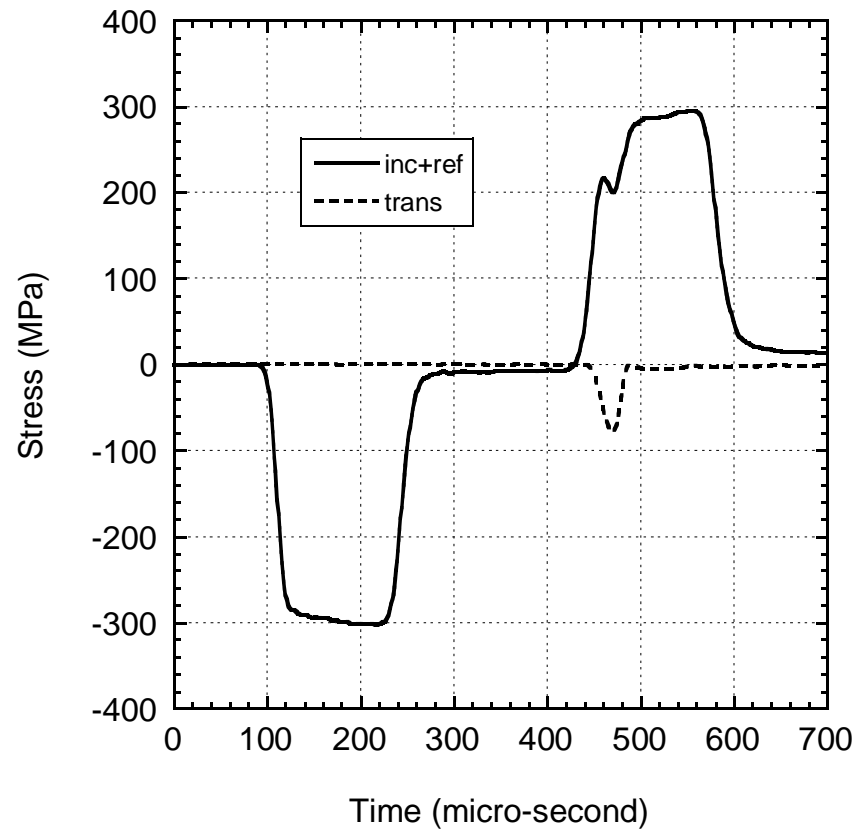

(a)

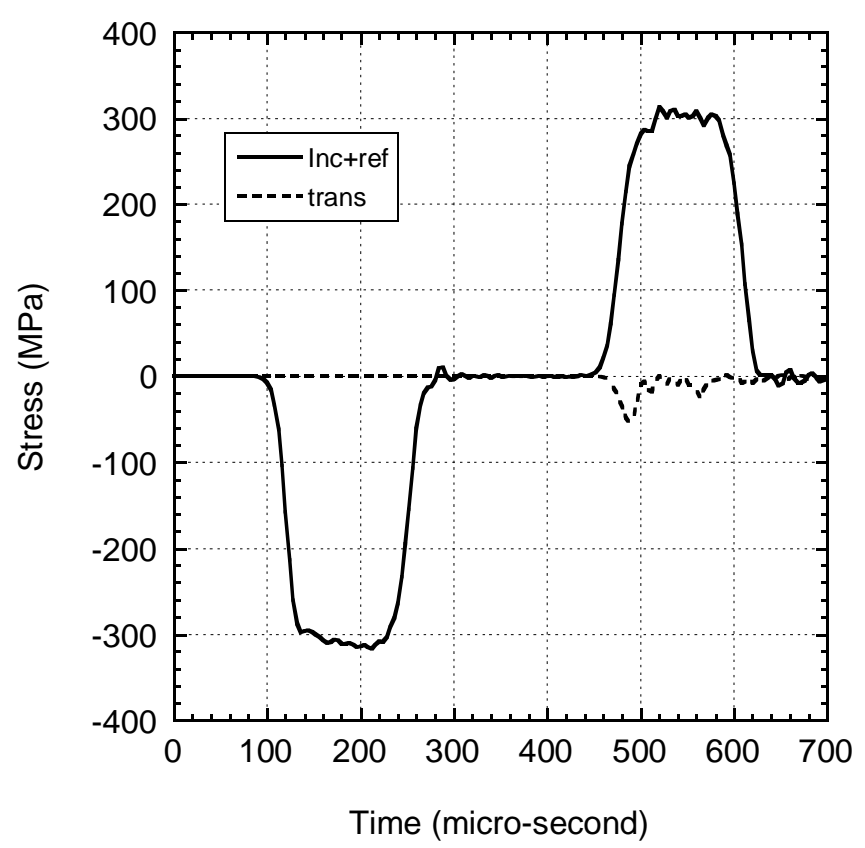

(b)

Figure. 11. SHPB TEST RESULTS IN IN-PLANE DIRECTION: (a) EXPERIMENTAL and (b) NUMERICAL. 


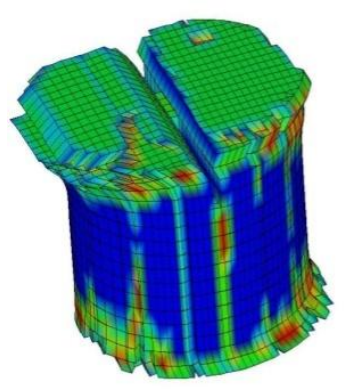

(a)

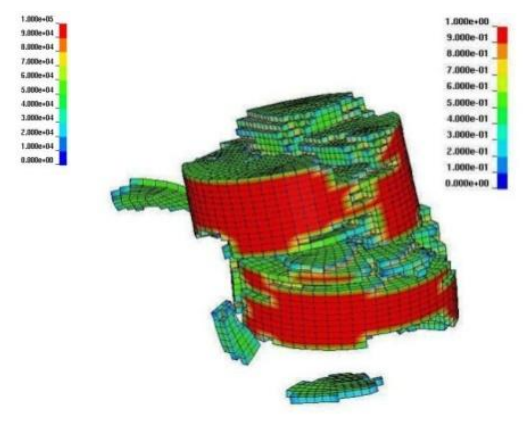

(b)
Fig. 12. CONTOURS of PROGRESSIVE DELAMINATION DAMAGE: (a) IN-PLANE SPECIMEN and (b) THROUGH THICKNESS SPECIMEN.

\section{CONCLUSIONS}

In this study quasi-static $\left(\sim 10^{-3} \mathrm{~s}^{-1}\right)$ and high strain rate $\left(\sim 850 \mathrm{~s}^{-1}\right)$ compression behavior of an E-glass/polyester composite were determined in the through-thickness and inplane directions. At higher strain rates an increased modulus and failure strength were observed in both directions. Higher strain rate sensitivity for both elastic modulus and failure strength was observed in the in-plane direction. A numerical model has been developed to investigate the compressive deformation and fracture of an E-glass/polyester composite. Excellent agreement has been demonstrated for the case of high strain rate loading. Also, the fracture geometries were successfully predicted with the numerical model.

\section{ACKNOWLEDGMENTS}

The authors would like to thank the Scientific and Technical Council of Turkey (TUBITAK) for the grant \# $106 \mathrm{M} 353$.

\section{REFERENCES}

[1] Deka, L.J., S.D. Bartus, and U.K. Vaidya, 2008, "Damage evolution and energy absorption of E-glass/polypropylene laminates subjected to ballistic impact." Journal of Materials Science. 43(13), pp. 4399-4410.

[2] Deka, L.J., S.D. Bartus, and U.K. Vaidya, 2009, "Multisite impact response of S2-glass/epoxy composite laminates." Composites Science and Technology. 69(6), pp. 725-735.

[3] Elmarakbi, A.M., N. Hu, and H. Fukunaga, 2009, "Finite element simulation of delamination growth in composite materials using LS-DYNA." Composites Science and Technology. 69(14), pp. 2383-2391.

[4] Forghani, A. and R. Vaziri, 2009, "Computational Modeling of Damage Development in Composite Laminates Subjected to Transverse Dynamic Loading." Journal of Applied Mechanics-Transactions of the Asme. 76(5).
[5] Grujicic, M., et al., 2009, "Multi-scale ballistic material modeling of cross-plied compliant composites." Composites Part B: Engineering. 40(6), pp. 468-482.

[6] Tasdemirci, A. and I.W. Hall, 2006, "Numerical and experimental studies of damage generation in a polymer composite material at high strain rates." Polymer Testing. 25(6), pp. 797-806.

[7] Xiao, X.R., 2009, "Modeling Energy Absorption with a Damage Mechanics Based Composite Material Model." Journal of Composite Materials. 43(5), pp. 427-444.

[8] Akil, Ö., et al., 2003, "Effect of strain rate on the compression behaviour of a woven fabric S2-glass fiber reinforced vinyl ester composite." Polymer Testing. 22(8), pp. 883-887.

[9] Kammerer, C. and A. Neme, 1998, "Plane behavior of an E-glass/polyester composite at high strain rates." Composites Science and Technology. 58(5), pp. 717-725.

[10] Lataillade, J.L., et al., 1996, "Effects of the intralaminar shear loading rate on the damage of multi-ply composites." International Journal of Impact Engineering. 18(6), pp. 679699.

[11] Naik, N.K., et al., 2007, "Interlaminar shear properties of polymer matrix composites: Strain rate effect." Mechanics of Materials. 39(12), pp. 1043-1052.

[12] Naik, N.K. and V.R. Kavala, 2008, "High strain rate behavior of woven fabric composites under compressive loading." Materials Science and Engineering a-Structural Materials Properties Microstructure and Processing. 474(12), pp. 301-311.

[13] Oguni, K. and G. Ravichandran, 2001, "Dynamic compressive behavior of unidirectional E-glass/vinylester composites." Journal of Materials Science. 36(4), pp. 831838.

[14] Hashin, Z., 1980, "Failure Criteria for Unidirectional Fiber Composites." Journal of Applied Mechanics. 47(2), pp. 329-334.

[15] Matzenmiller, A., J. Lubliner, and R.L. Taylor, 1995, "A constitutive model for anisotropic damage in fibercomposites." Mechanics of Materials. 20(2), pp. 125-152.

[16] Xiao, J.R., B.A. Gama, and J.W. Gillespie, 2007, "Progressive damage and delamination in plain weave $S-2$ glass/SC-15 composites under quasi-static punch-shear loading." Composite Structures. 78(2), pp. 182-196.

[17] Pahr, D.H., et al., 2002, "A study of short-beam-shear and double-lap-shear specimens of glass fabric/epoxy composites." Composites Part B: Engineering. 33(2), pp. 125-132.

[18] LS-DYNA: Keyword User's Manual Version 971. Vol. 1. 2007: Livermore Software Tech. Corp. 